\title{
Bullying victimization among preadolescents in a community-based sample in Canada: a latent class analysis
}

\author{
Adiba Ashrafi', Cindy Xin Feng ${ }^{2,4^{*}}$, Cory Neudorf ${ }^{3}$ and Khrisha B. Alphonsus ${ }^{4}$
}

\begin{abstract}
Objective: Bullying victimization among adolescents has been well-recognized as a behavior associated with adverse psychological and mental health outcomes. Most studies on bullying victimization have focused on adolescents, but research is sparse regarding school victimization among preadolescents before they transition to adolescence. This study sought to identify latent classes of different types of co-occurring bullying victimization, based on a sample of 3829 school students in grades 5-8, ages 9-14 in the year of 2011 from the Saskatoon Health Region, Saskatchewan, Canada.

Results: Using a latent class analysis approach, the results uncovered three groups of victimized students, including those who were aggressively victimized (7.2\%), moderately victimized (34.6\%) and non-victimized (58.2\%). Younger age and being overweight was associated with a higher likelihood of bullying victimization. Moderately and aggressively victimized students had greater probabilities of feeling like an outsider, experiencing anxiety, depressed moods, engaging in suicidal ideation and drinking when compared to non-victimized students. Peer and parent supports had significant protective effects against being victimized. Given the negative consequences of recurrent victimization among the preadolescents, it is imperative to address bullying incidents as they occur to prevent repeated transgressions, especially for those who suffer from multiple types of victimization.
\end{abstract}

Keywords: Latent class analyses, Bullying victimization, Suicidal ideation, Preadolescence, School violence

\section{Introduction}

Early adolescence, characterized as a phase of rapid physical and emotional growth, proves to be a difficult stage in life for children, as they are put at increased risk for bullying [1-3]. Bullying can be defined as inflicting intentional and repeated harm on someone when there is a real or perceived power imbalance [4]. There is growing evidence that bullying victimization among youths may have numerous negative mental health consequences,

\footnotetext{
*Correspondence: cindy.feng@uottawa.ca

${ }^{2}$ School of Epidemiology and Public Health, Faculty of Medicine,

University of Ottawa, 600 Peter Morand Crescent, Ottawa, ON K1G 5Z3,

Canada

Full list of author information is available at the end of the article
}

including psychiatric problems, substance use, delinquency, and aggression [5-9].

There are different types of peer victimization such as a physical attack, verbal harassment, social exclusion, spreading rumors, and cyberbullying and students may suffer from multiple types of victimization simultaneously. Latent class analysis (LCA) has been often used to uncover the latent co-occurring patterns of various types of bullying victimizations while accounting for the measurement errors $[10,11]$. Understanding the nature of the latent classes of bullying victimization is essential to help schools develop prevention and intervention strategies for reducing bullying victimization. Previous research using LCA was often based on dichotomized responses of bullying occurrence; however, the frequency of repeated

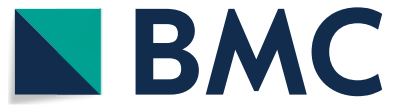

(c) The Author(s) 2020. This article is licensed under a Creative Commons Attribution 4.0 International License, which permits use, sharing, adaptation, distribution and reproduction in any medium or format, as long as you give appropriate credit to the original author(s) and the source, provide a link to the Creative Commons licence, and indicate if changes were made. The images or other third party material in this article are included in the article's Creative Commons licence, unless indicated otherwise in a credit line to the material. If material is not included in the article's Creative Commons licence and your intended use is not permitted by statutory regulation or exceeds the permitted use, you will need to obtain permission directly from the copyright holder. To view a copy of this licence, visit http://creativeco mmons.org/licenses/by/4.0/. The Creative Commons Public Domain Dedication waiver (http://creativecommons.org/publicdomain/ zero/1.0/) applies to the data made available in this article, unless otherwise stated in a credit line to the data. 
victimization reflects the severity of the bullying victimization, which should also be considered. Moreover, most studies using LCA to date have been conducted with children older than 10 years of age and middle school students $[10,11]$. Research that focuses on a slightly younger age group is still relatively scarce.

To address the abovementioned gaps in the literature, the first purpose of our study was to uncover the latent classes of bullying victimization based on the self-reported bullying frequency according to the types of bullying victimizations (physical, verbal, social exclusion, and cyberbullying) through a series of LCA models among a community-based sample of preadolescents aged 9-14. The second purpose of this study is to identify factors associated with latent class membership.

\section{Main text Methods}

A cross-sectional study was conducted among students, attending grades 5 to 8, ages 9-14 years based on the student health survey from the Saskatoon Health Region in Saskatchewan, Canada. A total of 5783 students (46.7\%) responded. The final study sample included 3829 students, who completed the questions of interest related to bullying victimizations, socio-demographics, behavior, psychological, and relationship variables. Flowchart of exclusion criteria to arrive at the final analytic sample was reported in Figure S1 in Additional file 1. Four different types of bullying victimizations were measured: physically (i.e. hitting, pinching, kicking), verbally (i.e. spreading rumors, gossiping, insulting and teasing), socially (i.e. isolating and excluding others from the group) and electronically (i.e. threaten through the Internet, e-mail, phone or cellular phone text messages) in the past 4 weeks. There are four potential responses: never in 4 weeks, once or twice in 4 weeks, every week, or many times a week. Due to the small number of students who reported being bullied either every week or many times a week, these two categories were combined.

Previous studies have applied socio-ecological systems theory [12] to understand the determinants of bullying involvement, which are multi-level contexts that include individual characteristics (i.e. sociodemographic characteristics, behavior, and mental health variables), microsystem (interpersonal relationships of individuals within immediate settings, i.e. parental-youth relationship or peer relationships) [10]. In this study, individual-level factors include socio-demographic variables (gender, grade, school location, duration of stay in Canada, Aboriginal status, father's employment status, mother's employment status, living situation, and the number of schools attended in the past year), body weight (overweight/normal or underweight) based on self-reported weight and height, behavior variables (smoking and drinking behaviors where "never" individuals were compared to those who had "tried" the particular activity) and psychological variables including suicide ideation in the past year, feeling like an outsider, depressed mood (12-question scale shortened from the Centre for Epidemiological Studies Depression Scale (CES-D), ranging from 0 to 36), anxiety (eight-question scale ranging from 0 to 28), and self-esteem (five-question scale ranging from 0 to 20). Microsystem factors include the quality of relationships with parents and friends, which were categorized into poor, moderate, and good.

LCA was used to distinguish groups of students by bullying frequency according to different types of bullying $[11,13]$. Bayesian information criterion (BIC) was measured to evaluate model fit, and the Vuong-Lo-Mendell-Rubin and the adjusted Lo-Mendell-Rubin likelihood ratio tests were used to compare between models of varying latent class size. Significant p-values in these tests suggest that the estimated model fits the data better than a model with one fewer group. LCA was run using the statistical software Mplus 7 [14]. Following LCA, multivariable multinomial regression of the latent class memberships was conducted to identify their important determinants using SPSS 24.0. Only significant explanatory variables at the $5 \%$ level of significance were included in the final model.

\section{Results}

Using LCA, 2-, 3-, and 4-class models were considered to identify the latent classes of study participants by the bullying frequency according to different types of bullying victimization (Table 1). The 3-class model had the smallest BIC, making it the preferred model. The Vuong-LoMendell-Rubin and the Adjusted Lo-Mendell-Rubin tests demonstrated that the model fit improved as additional groups were added from the 2-class model through to the 4-class model. However, the 4-class model $(\mathrm{p}<0.05)$ was not as statistically significant as the 3-class model $(\mathrm{p}<0.0001)$.

Altogether, the 3-class model was chosen including latent classes: (1) non-victimized, (2) moderately victimized, and (3) aggressively victimized (Table 2 ). The probability of students belonging to each group was $58.2 \%$,

\section{Table 1 Latent class analysis fit indices}

\begin{tabular}{llll}
\hline Model selection criteria & 2-Class & 3-Class & 4-Class \\
\hline BIC & $26,628.755$ & $25,967.137$ & $25,994.400$ \\
VUONG-LO-MENDELL-RUBIN LRT & $p<0.0001$ & $p<0.0001$ & $p=0.0158$ \\
LO-MENDELL-RUBIN ADJUSTED & $p<0.0001$ & $p<0.0001$ & $p=0.0166$ \\
LRT & & &
\end{tabular}

$B I C$ Bayesian information criterion, $L R T$ likelihood ratio test 
Table 2 Item-response probabilities for latent classes of bullying frequencies according to different types of bullying victimization

\begin{tabular}{|c|c|c|c|c|c|}
\hline \multirow[t]{2}{*}{ Types of bullying } & \multirow[t]{2}{*}{ Bullying frequency } & \multirow[t]{2}{*}{ Overall average } & \multicolumn{3}{|c|}{$\begin{array}{l}\text { Latent class } \\
\text { Item-response probabilities }\end{array}$} \\
\hline & & & Non-victimized & $\begin{array}{l}\text { Moderately } \\
\text { victimized }\end{array}$ & $\begin{array}{l}\text { Aggressively } \\
\text { victimized }\end{array}$ \\
\hline \multirow[t]{3}{*}{ Physical } & Never & 0.791 & 0.965 & 0.628 & 0.254 \\
\hline & Once or twice & 0.180 & 0.035 & 0.356 & 0.445 \\
\hline & Every week/many times a week & 0.029 & 0.000 & 0.016 & 0.301 \\
\hline \multirow[t]{3}{*}{ Verbal } & Never & 0.600 & 0.901 & 0.241 & 0.021 \\
\hline & Once or twice & 0.301 & 0.099 & 0.658 & 0.173 \\
\hline & Every week/many times a week & 0.099 & 0.000 & 0.100 & 0.806 \\
\hline \multirow[t]{3}{*}{ Social } & Never & 0.713 & 0.969 & 0.439 & 0.085 \\
\hline & Once or twice & 0.218 & 0.029 & 0.531 & 0.193 \\
\hline & Every week/many times a week & 0.069 & 0.003 & 0.031 & 0.722 \\
\hline \multirow[t]{3}{*}{ Electronic } & Never & 0.901 & 0.989 & 0.830 & 0.573 \\
\hline & Once or twice & 0.079 & 0.011 & 0.155 & 0.237 \\
\hline & Every week/many times a week & 0.020 & 0.000 & 0.015 & 0.191 \\
\hline Latent class prevalence & & & 0.582 & 0.346 & 0.072 \\
\hline
\end{tabular}

$34.6 \%$, and $7.2 \%$, respectively. Among non-victimized children, the likelihood of never being bullied physically was $96.5 \%$, verbally was $90.1 \%$, socially was $96.9 \%$, and electronically was $98.9 \%$. In contrast, for the moderately victimized group, the probability of being bullied once or twice physically was $35.6 \%$, verbally was $65.8 \%$, socially was $53.1 \%$, and electronically was $15.5 \%$. Among aggressively victimized children, the probability of being frequently bullied physically was $30.1 \%$, verbally was $80.6 \%$, socially was $72.2 \%$, and electronically was $19.1 \%$. Additionally, the likelihood of these same children experiencing once or twice physical bullying, $44.5 \%$, and occasional electronic bullying, $23.7 \%$, was higher than the norm. The demographic characteristics by latent class membership are presented in Table S1 in Additional file 1.

The results of evaluating the correlates of the class memberships based on multivariable multinomial regression (Table 3) indicated that preadolescents in grades 5-7 were more likely to be moderately and aggressively bullied than those in grade 8 . Also, males were more likely to be aggressively victimized than females (OR: 1.79 , CI 1.26-2.54), when compared to the non-victimized group, but this association was not evident among the moderately victimized group. In contrast, residency status, Aboriginal status, parents' employment status, living situation, and changing schools were not significant explanatory variables of victimization, and thus, were excluded from the final model.

Preadolescents with self-perception of being overweight were 1.48 (95\% CI 1.18-1.86) and 2.31 (95\% CI 1.57-3.40) times more likely to be moderately and aggressively victimized versus non-victimized, respectively. Aggressively victimized children were 2.14 (95\% CI 1.18-3.87) times more likely than non-victimized to have suicide ideation. In both moderately victimized (OR: 3.20, 95\% CI 2.82-3.63) and aggressively victimized groups (OR: 10.55, 95\% CI 8.37-13.29) subgroups, preadolescents were more prone to feel like an outsider when compared to the non-victimized group. For every score increase in depressive symptom, the odds of being aggressively victimized was 1.10 (95\% CI $1.05-1.15)$ times more likely than the odds of being non-victimized. Similarly, for every score increase in the level of reported anxiety symptoms, preadolescents were more likely to be moderately victimized (OR: 1.09, 95\% 95\% CI 1.05-1.13) and aggressively victimized (OR: 1.13, 95\% CI 1.07-1.20) than non-victimized. Self-esteem was not a significant correlate of membership for any of the identified latent classes. For behavioral patterns, drinkers were more likely to be moderately victimized (OR: $1.91,95 \%$ CI $1.55-2.35$ ) and aggressively victimized (OR: $2.87,95 \%$ CI 1.92-4.28) than non-victimized. Smoking was not associated with the identified latent class memberships.

A protective effect was observed among students who had better relationships with their parents. For every score increase in parent relationship, the odds of belonging to the moderately victimized class were 0.95 (95\% CI 0.93-0.97) times and the odds of belonging to the aggressively victimized class were 0.95 (95\% CI $0.91-0.99)$ times the odds of being non-victimized. The protective effect was greater for students who had many friends and who got along with their peers. For those with better 
Table 3 Multivariable analysis for evaluating the correlates of the latent class memberships $(n=3829)$

\begin{tabular}{|c|c|c|c|c|}
\hline \multirow[t]{2}{*}{ Covariates } & \multicolumn{2}{|c|}{$\begin{array}{l}\text { Moderately victimized }(n=1326) \text { vs. } \text { non-victimized } \\
(n=2228)\end{array}$} & \multicolumn{2}{|c|}{$\begin{array}{l}\text { Aggressively victimized }(n=275) \text { vs. non- } \\
\text { victimized }(n=2228)\end{array}$} \\
\hline & Odds ratio $(95 \% \mathrm{Cl})$ & $p$-value & Odds ratio $(95 \% \mathrm{Cl})$ & $p$-value \\
\hline \multicolumn{5}{|l|}{ Gender } \\
\hline Male & $0.98(0.83-1.16)$ & 0.815 & $1.79(1.26-2.54)$ & 0.001 \\
\hline Female & 1.00 & - & 1.00 & - \\
\hline \multicolumn{5}{|l|}{ Grade } \\
\hline Grade 5 & $2.06(1.60-2.65)$ & $<0.001$ & $3.85(2.29-6.49)$ & $<0.001$ \\
\hline Grade 6 & $1.83(1.44-2.33)$ & $<0.001$ & $3.04(1.85-4.98)$ & $<0.001$ \\
\hline Grade 7 & $1.81(1.43-2.28)$ & $<0.001$ & $2.58(1.57-4.27)$ & $<0.001$ \\
\hline Grade 8 & 1.00 & - & 1.00 & - \\
\hline \multicolumn{5}{|l|}{ Self-weight perception } \\
\hline Overweight & $1.48(1.18-1.86)$ & 0.001 & $2.31(1.57-3.40)$ & $<0.001$ \\
\hline Normal or Underweight & 1.00 & - & 1.00 & - \\
\hline \multicolumn{5}{|l|}{ Suicide ideation in past year } \\
\hline Yes & $1.55(1.00-2.40)$ & 0.053 & $2.14(1.18-3.87)$ & 0.012 \\
\hline No & 1.00 & - & 1.00 & - \\
\hline Feeling like an outsider & $3.20(2.82-3.63)$ & $<0.001$ & $10.55(8.37-13.29)$ & $<0.001$ \\
\hline Depressed mood & $1.02(1.00-1.05)$ & 0.105 & $1.10(1.05-1.15)$ & $<0.001$ \\
\hline Anxiety & $1.09(1.05-1.13)$ & $<0.001$ & $1.13(1.07-1.20)$ & $<0.001$ \\
\hline \multicolumn{5}{|l|}{ Drinking } \\
\hline Yes & $1.91(1.55-2.35)$ & $<0.001$ & $2.87(1.92-4.28)$ & $<0.001$ \\
\hline No & 1.00 & - & 1.00 & - \\
\hline Parent relationship & $0.95(0.93-0.97)$ & $<0.001$ & $0.95(0.91-0.99)$ & 0.013 \\
\hline Friendships & $0.89(0.86-0.92)$ & $<0.001$ & $0.87(0.82-0.92)$ & $<0.001$ \\
\hline
\end{tabular}

friendships, the odds of being moderately and aggressively victimized were 0.89 (95\% CI $0.86-0.92)$ times and 0.87 (95\% CI 0.82-0.92) times the odds of being non-victimized, respectively.

\section{Discussion}

The main strength of this study is that the LCA method was applied to bullying frequency according to different types of bullying rather than based on dichotomized bullying variables. The second strength is the current study focused on preadolescents before they transition to adolescence. Another strength is the use of communitybased data containing rich information on a broad spectrum of determinants. Such data are rarely reported in the preadolescent literature.

Consistent with previous research, our findings further illustrate that students in younger grades were bullied more often versus students from older grades $[1,15,16]$. With the exception of students who display difficulties navigating this transitory period or who have social information-processing deficits, it is not surprising to observe greater victimization occurring in lower grades, where peer relations and peer group structure play a more salient role [1]. These results suggest the need for prevention and intervention efforts that might need to start as early as grade five. Our findings provide insight that being simultaneously bullied in multiple ways is common at this age. No significant gender and race differences were identified in association with latent class memberships.

This study provided further evidence of suicide ideation in the past year was significant among students who were aggressively victimized. Previous research found that risky suicidal behaviors were equally associated with non-physical bullying victims (e.g. verbal, social, cyber) as they were to physical bullying victims, despite extant research that contested relational aggression to be more causal of suicide ideation [17]. Besides suicide ideation, aggressively victimized students in this investigation were also more likely to display depressed mood symptomatology and report anxiety. Students who felt like an outsider at school had significantly higher chances of being either moderately or aggressively bullied, but especially the latter. This reaffirms findings from prior research, which suggest that victims exhibit tendencies to internalize their feelings [10] and that these feelings of not belonging combined with a poor bullying climate (e.g. perceived adult support) elevates the risk of being bullied often [18, 19]. 
Self-perception of being overweight is yet another factor that is more common in the moderately and aggressively victimized subgroups, which is consistent with present literature on discrimination towards individuals struggling with their body image and weight [20]. Weight loss preoccupation is common among bullies, victims, and bully-victims [4].

Drinking behavior was also found to be significantly associated with peer victimization, which may act as a coping mechanism for preadolescents who are bullied. Conversely, it is also possible that preadolescents who partake in underage drinking are more likely to be targeted for social exclusion, prejudice from their peers, etc.

Preadolescents, who had a stronger social network with peers and better relationships with their parents were less likely to be bullied because they could confide in their peers or parents when they faced challenges [21]. In turn, their peers could help them prevent and address bullying-related occurrences [2].

\section{Limitations}

Due to the cross-sectional nature of this study, causal inferences cannot be drawn. Additionally, the questions on bullying type and frequency in the survey were asked for the past month; therefore, bullied earlier in the year or even bullied ever were not captured. Furthermore, perception of what constitutes bullying is highly variable from student to student, especially for verbal, social, and electronic bullying. A valid and reliable bullying assessment tool should be employed to obtain more accurate results $[10,13]$. Finally, information on the contextual factors, such as including school and community characteristics are also very limited in this dataset.

\section{Supplementary information}

Supplementary information accompanies this paper at https://doi. org/10.1186/s13104-020-04989-4.

Additional file 1. Additional figure and table.

\section{Abbreviations}

LCA: Latent class analysis; CES-D: Centre for epidemiological studies depression scale; BIC: Bayesian information criterion.

\section{Acknowledgements}

We thank the Saskatoon Public School Board, the Greater Saskatoon Catholic School Board, the Saskatoon Tribal Council and the Saskatoon Health Region for supporting this research. We also acknowledge the Canadian Institutes of Health Research as the funding source for the original survey.

\section{Authors' contributions}

AA and CF conceived of the study conducted the analyses and wrote the manuscript. CF supervised the designing of the study, data analyses and interpretation of findings and contributed to writing the manuscript. CN and $K A$ revised the manuscript substantively for important intellectual content. All authors read and approved the final manuscript.

\section{Funding}

The design and the collection of the original data for the Student Health Survey were funded by the Canadian Institutes of Health Research. No funding was received for the design, analysis, and interpretation of data for this current study and in writing the manuscript.

\section{Availability of data and materials}

The data that support the findings of this study are available from Saskatoon Health Region Public Health Observatory, but restrictions apply to the availability of these data, which were used under license for the current study, and so are not publicly available. Data are however available from the Saskatoon Health Region Public Health Observatory upon reasonable request.

\section{Ethics approval and consent to participate}

This study received ethics approval by the Behavioural Research Ethics Board at the University of Saskatchewan. A four-stage informed consent protocol was employed. Written consent was obtained from both School Divisions. Verbal consent was obtained from the Principal of each school. If these consents were obtained, written informed consent was obtained from parents. If the parent approved, written informed consent was obtained from each child prior to starting the survey. Although the four-stage informed consent policy ensured that the children were protected, this extensive consent protocol most likely resulted in lower participation rates.

\section{Consent to publish}

Not applicable.

\section{Competing interests}

The authors declare that they have no competing interests.

\section{Author details}

${ }^{1}$ Mailman School of Public Health, Columbia University, New York, USA. ${ }^{2}$ School of Epidemiology and Public Health, Faculty of Medicine, University of Ottawa, 600 Peter Morand Crescent, Ottawa, ON K1G 5Z3, Canada. ${ }^{3}$ Health Surveillance \& Reporting, Saskatchewan Health Authority, Community Health and Epidemiology, University of Saskatchewan, Saskatoon, SK, Canada.

${ }^{4}$ School of Public Health, University of Saskatchewan, Saskatoon, Canada.

Received: 8 January 2020 Accepted: 27 February 2020

Published online: 07 March 2020

\section{References}

1. Bettencourt AF, Farrell AD. Individual and contextual factors associated with patterns of aggression and peer victimization during middle school. J Youth Adolesc. 2013;42:285-302.

2. Lawson MA, et al. Analyzing sub-population profiles and risk factors for school bullying. Child Youth Serv Rev. 2013;35:973-83.

3. Williford AP, et al. Patterns of aggressive behavior and peer victimization from childhood to early adolescence: a latent class analysis. J Youth Adolesc. 2011;40:644-55.

4. Lee $\mathrm{K}$, et al. Does psychological functioning mediate the relationship between bullying involvement and weight loss preoccupation in adolescents? A two-stage cross-sectional study. Int J Behav Nutr. 2017;14:1-11.

5. Cross D, Lester L, Barnes A. A longitudinal study of the social and emotional predictors and consequences of cyber and traditional bullying victimisation. Int J Public Health. 2015;60:207-17.

6. Wolke D, Lereya ST. Long-term effects of bullying. Arch Dis Child. 2015;100(9):879-85.

7. Olweus D. Bullying at School. In: Huesmann LR, editor. Aggressive behavior. Boston: Springer; 1994.

8. Cross D, Lester L, Barnes A. A longitudinal study of the social and emotional predictors and consequences of cyber and traditional bullying victimisation. Int J Public Health. 2015;60(2):207-17.

9. Mishna F, et al. Cyber bullying behaviors among middle and high school students. Am J Orthopsychiatry. 2010;80(3):362-74.

10. Lovegrove PJ, Henry KL, Slater MD. Examination of the predictors of latent class typologies of bullying involvement among middle school students. J School Viol. 2012;11:75-93. 
11. Wang J, lannotti RJ, Luk JW. Patterns of adolescent bullying behaviors: physical, verbal, exclusion, rumor, and cyber. J Sch Psychol. 2012;50:521-34.

12. Bronfenbrenner $U$, Morris PA. The ecology of developmental processes. In: Lerner RM, editor. Theoretical models of human development handbook of child psychology. 5th ed. New York: Wiley; 1998. p. 993-1028.

13. Nylund $K$, et al. Subtypes, severity, and structural stability of peer victimization: what does latent class analysis say? Child Dev. 2007;78(6):1706-22.

14. Muthén B, Muthén LK. Integrating person-centered and variable-centered analyses: growth mixture modeling with latent trajectory classes. Alcohol Clin Exp Res. 2000;24(6):882-91.

15. Boulton MJ, Underwood K. Bully/victim problems among middle school children. Br J Educ Psychol. 1992;62:73-87.

16. Bradshaw CP, Waasdorp TE, O'Brennan LM. A latent class approach to examining forms of peer victimization. J Educ Psychol. 2013;105:839-49.

17. Roh B-R, et al. The structure of co-occurring bullying experiences and associations with suicidal behaviors in Korean adolescents. PLOS ONE. 2015;10:1-14
18. Goldweber A, Waasdorp TE, Bradshaw CP. Examining the link between forms of bullying behaviors and perceptions of safety and belonging among secondary school students. J Sch Psychol. 2013;51:469-85.

19. Lam S-F, et al. A latent class growth analysis of school bullying and its social context: the self-determination theory perspective. School Psychol Q. 2015;30(1):75-90.

20. Garnett BR, et al. The intersectionality of discrimination attributes and bullying among youth: an applied latent class analysis. J Youth Adolesc. 2014:43:1225-39.

21. Gage NA, Prykanowski DA, Larson A. School climate and bullying victimization: a latent class growth model analysis. Sch Psychol Q. 2014;29(3):256-71.

\section{Publisher's Note}

Springer Nature remains neutral with regard to jurisdictional claims in published maps and institutional affiliations.
Ready to submit your research? Choose BMC and benefit from:

- fast, convenient online submission

- thorough peer review by experienced researchers in your field

- rapid publication on acceptance

- support for research data, including large and complex data types

- gold Open Access which fosters wider collaboration and increased citations

- maximum visibility for your research: over $100 \mathrm{M}$ website views per year

At BMC, research is always in progress.

Learn more biomedcentral.com/submissions 